\title{
Prevalence of cardiovascular risk factors and socioeconomic level among public-sector workers in Angola
}

Daniel P Capingana', Pedro Magalhães ${ }^{1}$, Amílcar BT Silva', Mauer AA Gonçalves², Marcelo P Baldo', Sérgio L Rodrigues ${ }^{1}$, Cristóvão CF Simões ${ }^{2}$, Albano VL Ferreira ${ }^{2}$ and José G Mill ${ }^{1 *}$

\begin{abstract}
Background: Cardiovascular diseases are the leading cause of death in the majority of developed and developing countries. African countries are currently facing an increase in both cardiovascular and transmitted diseases. In addition, cardiovascular risk varies among different socioeconomic groups. Thus, we determined the prevalence of modifiable cardiovascular risk factors in apparently healthy public-sector workers and investigated possible relationships with socioeconomic status.

Methods: We employed a cross-sectional study comprising 42.2\% $(n=615)$ of the public-sector workers at Agostinho Neto University, 48\% ( $n=294)$ male and 52\% ( $n=321)$ female, with ages between 20 and 72 years and from various socioeconomic groups. The study was conducted from February 2009 to December 2010. Personal, anthropometric, biochemical, hemodynamic, socioeconomic, and physical activity data were collected.

Results: The prevalence rates of cardiovascular risk factors were as follows: hypertension, $45.2 \%$ (men 46.3\%, women 44.2\%, P > 0.05); hypercholesterolemia, $11.1 \%$ (men 10.5\%, women 11.5\%, P > 0.05); low high-density lipoprotein (HDL) cholesterol, 50.1\% (men 36.9\%, women 62.3\%; $\mathrm{P}<0.05$ ); hypertriglyceridemia, 10.6\% (men 12.6\%, women 8.7\%, P > 0.05); smoking, 7.2\% (men 10.2\%, women 4.4\%; $P<0.05$ ); diabetes, 5.7\% (men 5.5\%, women 5.9\%, P > 0.05); overweight, 29.3\% (men 27.3\%, women 31.2\%, P > 0.05); obesity, 19.6\% (men 9.2\%, women 29.0\%; $P<0.05$ ); sedentary lifestyle, 87.2\% (men 83.0\%, women 91,0\%, P < 0.05); and left ventricular hypertrophy, 20\% (men 32.0\%, women 9.0\%; $P<0.05$ ). At least one risk factor was present in $27.7 \%$ of the sample; $15.2 \%$ had two risk factors, and $31.4 \%$ had three or more risk factors. Among the individuals with low socioeconomic status, $41.0 \%$ had three or more risk factors.

Conclusions: The results of this study suggest the existence of a high prevalence of multiple risk factors for cardiovascular disease in apparently healthy public-sector workers in Angola. The workers in lower socioeconomic groups had higher incidences of hypertension, smoking, and left ventricular hypertrophy.
\end{abstract}

Keywords: Cardiovascular risk factors, Socioeconomic status, Angola

\section{Background}

Cardiovascular diseases (CVD) are the leading cause of death in the majority of developed and developing countries [1]. A century ago, CVD were responsible for less than $10 \%$ of all deaths, whereas today, it accounts for approximately $30 \%$ of deaths worldwide, including

\footnotetext{
* Correspondence: jose.mill@ufes.br

${ }^{1}$ Department of Physiological Sciences, Federal University of Espírito Santo, Espírito Santo, Brazil

Full list of author information is available at the end of the article
}

nearly $40 \%$ in high-income countries and approximately $28 \%$ in low-and middle-income countries. The global trend in deaths from CVD predicts an estimated rate of $32 \%$ for the year 2020, with a greater contribution from middle-and low-income countries compared with high-income countries [2].

The profile of CVD varies widely by country and region, and the age-adjusted mortality rates from are simultaneously declining in high-income countries and increasing in low-and middle-income countries [3].

\section{Biomed Central}


African countries are facing a rapid growth of CVD and have very limited resources for the creation of public health infrastructures similar to those existing in high-income countries. In addition, there are numerous national priorities that compete with the provision of this type of care, including the stimulation of economic growth, social and political changes, the devastation brought on by diseases such as HIV/AIDS in Sub-Saharan Africa [4], and inside conflicts of political and ethnic origin in several countries.

Socioeconomic status is a complex variable influenced by education, work experience, and financial performance. Nevertheless, clear variations in CVD risk have been reported among different socioeconomic groups $[5,6]$. The socioeconomic imbalances are reflected in other modifiable factors, such as overweight, obesity, and sedentary lifestyle, which are more prevalent in African-Americans than in other ethnic groups [7]. These conditions are linked to numerous comorbidities that affect CVD risk, such as dyslipidemia, hypertension, diabetes mellitus, and metabolic syndrome [8].

Angola is a country with a life expectancy of 50.3 years [9] and an infant mortality rate of 193.5 per 1,000 children under 5 years of age [10]. In addition to infectious and parasitic diseases, the residents continue to suffer the consequences of the civil war that lasted 41 years and resulted in destruction of the health care and education infrastructure, forced the relocation of people to safer places, and caused the disintegration of many families. All these factors may ultimately contribute to increase the CVD burden. Due to the limited information on CVD in Angola, we decided to determine the prevalence and severity of modifiable cardiovascular risk factors in a sample of apparently healthy public-sector workers at Agostinho Neto University (UAN) in Luanda, Angola, and to investigate the relationships of these factors with socioeconomic status of participants.

\section{Methods}

This study was a cross-sectional, descriptive study of a sample of public-sector working at UAN in Luanda, Angola. The selection of this sample of public-sector workers should facilitate study follow-up because this population is relatively stable.

The research was conducted in accordance with national and international ethical guidelines and approved by the Independent Ethics Committee of the School of Medicine of UAN.

UAN is a public institution of higher education employing 1,458 domestic public-sector workers, of which $49.7 \%(\mathrm{n}=724)$ are teachers $(514$ males and 210 females) and $50.3 \%(\mathrm{n}=734)$ are staff (359 males and 375 females), with ages between 20 and 72 years. All workers were invited to participate, and our goal was to include $50 \%(n=729)$ of the eligible population. However, due to difficulties to enroll participants living far from the data collect centre, the study enrolled $42.2 \%(n=615)$ of the eligible population ( $48 \%$ men and $52 \%$ women). The sampling method was developed in two stages. The first stage consisted of sending an invitation letter from the Dean of UAN to the chairs of the Schools and Institutes of UAN to promote the study among all public-sector workers and invite them to participate in the study. The second phase consisted of publicizing the study via pamphlets, posters, and meetings between the research team and groups of workers in various public educational institutions. The participation of each public-sector worker in the project was voluntary and was preceded by the reading and signing of an informed consent form. The study was conducted at the Department of Physiological Sciences Teaching and Research at the Medical School of UAN. Three employees from the abovementioned department were trained to obtain all data, including standard measurements of blood pressure, anthropometric parameters, acquisition of electrocardiogram recordings, and assisting of the respondents in correctly completing the questionnaire. Training and certification of staff investigators was conducted by an experienced researcher over five days.

Data were collected from February 2009 to December 2010 based on a modified questionnaire used in the WHO-MONICA Project and on the WHO manuals for stepwise approaches and the surveillance of nontransmitted diseases [11].

Personal, anthropometric, biochemical, hemodynamic, socioeconomic, and physical activity data were collected. The socioeconomic status was classified into quartiles according to average monthly household income [12]: 1st quartile (low socioeconomic class), 2nd quartile (middle class), 3rd quartile (upper middle class), and 4th quartile (upper class). Education was classified into three levels based on the number of years of education: low ( $\leq 4$ years of education), middle (5-12 years of education), and high ( $\geq 13$ years of education).

Individuals who reported use of tobacco (cigarette, cigar, or pipe) on a regular (daily smoking) or occasional basis and those who reported having stopped smoking 6 months prior to the day of the interview were considered as smokers. Individuals who did not report practicing sports for competition or engaging in physical activity for leisure lasting at least 30 minutes at a frequency of three days per week were considered sedentary $[13,14]$.

Systolic blood pressure (SBP) and diastolic blood pressure (DBP) were measured in the left arm by oscillometry three times in each individual, with a minimum interval between measurements of 10 minutes, using an OMRON (model HEM- 705CP,Tokyo, Japan) blood 
pressure monitor. SBP and DBP levels were calculated as the arithmetic mean of the last two measurements. The VII Joint National Committee criteria were used for BP classification [15]. Thus, individuals with SBP $\geq 140$ $\mathrm{mmHg}$ and/or with DBP $\geq 90 \mathrm{mmHg}$ were classified as hypertensive, in addition to the individuals taking antihypertensive medication, regardless of the frequency of use.

The body weight (W) of each participant was measured in kilograms $(\mathrm{kg})$ using a previously calibrated mechanical scale (SECA) with a maximum capacity of $220 \mathrm{~kg}$ and accuracy of 100 grams. The height $(\mathrm{H})$ of each participant was measured in centimeters $(\mathrm{cm})$ using a stadiometer fixed to the SECA scale with an accuracy of $0.5 \mathrm{~cm}$. The waist circumference (WC) and hip circumference (HC) were each measured twice with an inextensible, inelastic, 1-cm-wide tape measure. The following cutoff points were used for body mass index $\left(\mathrm{BMI}=\mathrm{W} / \mathrm{H}^{2}\right)[16]$ : low body weight, BMI $<18.5 \mathrm{~kg} / \mathrm{m}^{2}$; normal weight, BMI 18.5 to $24.9 \mathrm{~kg} / \mathrm{m}^{2}$; overweight, BMI 25 to $29.9 \mathrm{~kg} / \mathrm{m}^{2}$; and obese, BMI $30 \mathrm{~kg} / \mathrm{m}^{2}$.

Blood was collected after 10 to 12 hours fasting by deep vessel venipuncture. The plasma glucose level and the lipid profile were determined to obtain the total cholesterol, high-density lipoprotein cholesterol fraction (HDL-c), and triglyceride (TG) levels. The low-density lipoprotein cholesterol fraction (LDL-c) was calculated using the Friedewald equation [17] to triglycerides $<400$ $\mathrm{mg} / \mathrm{dL}$. The cutoff points used to define hypercholesterolemia stages, the reduction of the HDL-c fraction, and hypertriglyceridemia were those recommended by the Third Expert Panel on the Detection, Evaluation, and Treatment of High Blood Cholesterol in Adults [18]; namely, total cholesterol (TC) was considered high for values $\geq 240 \mathrm{mg} / \mathrm{dL}$, and the HDL-c fraction was considered low for values $<40 \mathrm{mg} / \mathrm{dL}$ in men and $<50 \mathrm{mg} / \mathrm{dL}$ in women. In addition, the LDL-c fraction was considered high for values $>160 \mathrm{mg} / \mathrm{dL}$.

The TG level was considered elevated at values $>150 \mathrm{mg} /$ $\mathrm{dL}$. The individuals with a glucose level $\geq 126 \mathrm{mg} / \mathrm{dL}$ or those under regular use of insulin and/or oral hypoglycemic agents were classified as diabetic. Fasting glucose levels between 110 and $125 \mathrm{mg} / \mathrm{dL}$ were considered indicative of impaired glucose tolerance [19].

Participants underwent conventional electrocardiogram recording at rest using a computerized device (Schiller ${ }^{\circledR}$ AT-10 EKG, Baar, Switzerland) with 12 leads, which allowed for the automatic retrieval of several measurements. The Sokolow-Lyon- Rappaport index (SV1 or SV2 + RV5 or RV6) was used to classify individuals as having left ventricular hypertrophy (LVH), which was considered to be present when the index was $>3.5 \mathrm{mV}$ [20].

For continuous variables, the mean difference between genders was analyzed using the Student's $t$-test for independent samples. The chi-squared $\left(\mathrm{X}^{2}\right)$ test was used for dichotomous variables (smoking, diabetes, and LVH) and the comparison of the proportions of the main cardiovascular risk factors among the groups. A one-way analysis of variance (ANOVA) was used to determine differences between three or more categorized groups. The analysis of differences within each ANOVA was conducted using Tukey's post hoc test. An analysis of covariance (ANCOVA) was used to assess the effects of age and gender on BMI, SBP, and DBP in the different socioeconomic groups, as well as the effects of SBP and gender on the Sokolow-Lyon indices of the groups. The significance level for all tests was set at alpha $<0.05$. Statistical analyses were performed using SPSS for Windows version 16.0.

\section{Results}

Table 1 lists the demographic characteristics of the 615 individuals (294 men and 321 women) included in the study, age ranging from $20-72$ years (age mean $=44.5 \pm$ 10.6 years, without significance difference between genders; $\mathrm{P}=0.176$ ). Individuals with a low educational level accounted for $34.6 \%$ of the sample population, those with a medium educational level constituted $24.4 \%$, and those with a high educational level constituted $41.0 \%$. Education levels were similarly distributed by genders $\left(\mathrm{X}^{2}=1.93, \mathrm{P}=0.926\right)$.

Mean values of WC $(80.1 \pm 12.9$ vs. $83.9 \pm 13.5 \mathrm{~cm}), \mathrm{HC}$ $(91.5 \pm 9.4$ vs. $99.5 \pm 11.4 \mathrm{~cm})$, and BMI $(24.1 \pm 4.3$ vs. $\left.27.1 \pm 5.8 \mathrm{~kg} / \mathrm{m}^{2}\right)$ were higher in the women $(\mathrm{P}<0.001)$.

With regard to WC, $39.8 \%$ of the sample showed values above the recommended level, and women had a significantly higher $(\mathrm{P}<0.05)$ proportion of high WC $(23.4 \%)$ and markedly high WC (38.9\%) compared with the values found in the men ( $8.8 \%$ vs. $6.5 \%)$. Regarding the biochemical data for the sample group, gender differences were found with regard to HDL level; namely, the women had a higher average value than the men $(47.6 \pm 11.2$ vs. $44.2 \pm$ $10.3 \mathrm{mg} / \mathrm{dL} ; \mathrm{P}<0.001)$. The mean blood glucose levels, total cholesterol, LDL, and TG were similar in both genders.

Table 2 shows the anthropometric, clinical, and biochemical characteristics according to the socioeconomic level. Age was different $(\mathrm{P}<0.001)$ among individuals of different socioeconomic groups. The three anthropometric indexes related to body weight increased $(\mathrm{P}<0.001)$ from the lowest to the upper socioeconomic group while blood pressure and the SKI showed an opposite tendency when only the three lowest classes were considered, even after adjustment for age and gender. In addition there were still differences in SBP and DBP after adjustment for age, gender, BMI, as well as in the SLI after adjustment for SBP, age, and gender. Biochemical variables, tended to 
Table 1 Demographic, anthropometric, and biochemical characteristics of the participants according to gender

\begin{tabular}{|c|c|c|c|c|}
\hline & Men & Women & $P$ & All \\
\hline N (\%) & $294(47.8)$ & $321(52.2)$ & 0.392 & $615(100)$ \\
\hline Age (years) & $45.1 \pm 11.1$ & $44.0 \pm 10.1$ & 0.176 & $44.5 \pm 10.6$ \\
\hline Educational level & & & 0.926 & \\
\hline Low & $110(37.4)$ & $103(32.1)$ & & $213(34.6)$ \\
\hline Medium & $69(23.5)$ & $81(25.2)$ & & $150(24.4)$ \\
\hline High & $115(39.1)$ & $137(42.7)$ & & $252(41.0)$ \\
\hline Socioeconomic class & & & 0.392 & \\
\hline Low & $81(27.6)$ & $73(22.7)$ & & $154(25.0)$ \\
\hline Middle & $77(26.2)$ & 79 (24.6) & & $156(25.4)$ \\
\hline Upper middle & $66(22.4)$ & $86(26.8)$ & & $152(24.7)$ \\
\hline Upper & $70(23.8)$ & $83(25.9)$ & & $153(24.9)$ \\
\hline$W C(\mathrm{~cm})$ & $80.1 \pm 12.9$ & $83.9 \pm 13.5$ & $<0.001$ & $82.1 \pm 13.3$ \\
\hline $\mathrm{HC}(\mathrm{cm})$ & $91.5 \pm 9.4$ & $99.5 \pm 11.4$ & $<0.001$ & $95.7 \pm 11.3$ \\
\hline BMI $\left(\mathrm{kg} / \mathrm{m}^{2}\right)$ & $24.1 \pm 4.3$ & $27.1 \pm 5.8$ & $<0.001$ & $25.7 \pm 5.4$ \\
\hline Glucose (mg/dL) & $94.9 \pm 20.0$ & $93.2 \pm 21.8$ & 0.313 & $94.0 \pm 21.0$ \\
\hline TC (mg/dL) & $189.5 \pm 41.4$ & $193.2 \pm 36.5$ & 0.240 & $191.5 \pm 38.9$ \\
\hline HDL-c (mg/dL) & $44.2 \pm 10.3$ & $47.6 \pm 11.2$ & $<0.001$ & $46.0 \pm 10.9$ \\
\hline LDL-c (mg/dL) & $125.0 \pm 41.8$ & $125.9 \pm 38.7$ & 0.796 & $125.5 \pm 40.2$ \\
\hline TG $(\mathrm{mg} / \mathrm{dL})$ & $101.7 \pm 41.7$ & $98.7 \pm 38.4$ & 0.340 & $100.2 \pm 40.0$ \\
\hline
\end{tabular}

WC waist circumference, $H C$ hip circumference, $B M I$ body mass index, $T C$ total cholesterol, HDL-c high density lipoprotein cholesterol, LDL-c low-density lipoprotein cholesterol, TG triglycerides, Proportions were expressed as number of individuals (percentage) and analyzed using the chi-square test. Continuous variables are reported as mean \pm standard deviation, and analyzed using the Student's t-test for independent samples. remain stable along socioeconomic levels, except for glucose levels which were significantly higher in the upper class.

The prevalence of cardiovascular risk factors according to gender is shown in Table 3.

The overall prevalence of hypertension was $45.2 \%$ $(\mathrm{n}=278)$, with similar proportion in men $(46.3 \%, \mathrm{n}=136)$ and women $(44.2 \%, \mathrm{n}=142)$. Higher prevalence of hypertension was found in the lowest socioeconomic classes (Table 4). The overall prevalence of hypercholesterolemia was $11.1 \%$, and the proportions were similar in both genders (men, 10.5\%; women, 11.5\%) and unrelated to socioeconomic classes.

The prevalence of high LDL levels did not differ between genders (men, 20.8\%; women, 18.9\%) or between socioeconomic classes. However, $24.8 \%$ of the participants had borderline values (men, 22.4\%; women, 26.9\%). There was an overall low HDL fraction prevalence of $50.1 \%$. This proportion was higher $\left(\mathrm{X}^{2}=3.840, \mathrm{P}<0.05\right)$ in women $(62.3 \%)$ than men (36.9\%). No significant differences were found between the socioeconomic classes regarding the prevalence of low HDL (low 46.8\%, middle 49.4\%, upper middle $46.1 \%$, upper $58.2 \%$; $\mathrm{P}=0.128$ ).

Hypertriglyceridemia was prevalent in approximately $10.6 \%$ of the entire sample, and the prevalence were similar between genders $\left(\mathrm{X}^{2}=2.422, \mathrm{P}=0.658\right)$ and among the four socioeconomic classes.

Active smoking was related by $7.2 \%$ of the sample (Table 3), with a higher proportion in men $($ men $=10.2 \%$ vs women $=$ 4.4\%; $\left.\mathrm{X}^{2}=4.430, \mathrm{P}<0.05\right)$. Prevalence of smoking decreased significantly from the lowest socioeconomic class to the upper one (14.3\% to $2.6 \% ; \mathrm{P}<0.001$, Table 4). Approximately $20.3 \%(n=125)$ of the sample group were former smokers, and more men $\left(\mathrm{X}^{2}=4 ; 43 ; \mathrm{P}<0.001\right)$ were former smokers $(28.6 \%, \mathrm{n}=84)$ than women $(12.8 \%, \mathrm{n}=41)$.

Table 2 Anthropometric, clinical, and biochemical characteristics according to the socioeconomic class

\begin{tabular}{|c|c|c|c|c|c|}
\hline Class & Low & Middle & Upper middle & Upper & $P$ \\
\hline N (\%) & $154(25.0)$ & $156(25.4)$ & $152(24.7)$ & $153(24.9)$ & 0.967 \\
\hline Age (years) & $48.4 \pm 9.7$ & $43.4 \pm 10.6$ & $40.3 \pm 10.6$ & $45.9 \pm 9.7$ & $<0.001$ \\
\hline$W C(\mathrm{~cm})$ & $77.6 \pm 12.7$ & $80.8 \pm 13.2$ & $82.9 \pm 13.4$ & $87.1 \pm 12.2$ & $<0.001$ \\
\hline $\mathrm{HC}(\mathrm{cm})$ & $90.5 \pm 11.0$ & $94.5 \pm 10.9$ & $97.2 \pm 10.5$ & $100.7 \pm 10.2$ & $<0.001$ \\
\hline BMI $\left(\mathrm{kg} / \mathrm{m}^{2}\right)$ & $23.9 \pm 5.0$ & $25.2 \pm 5.4$ & $26.1 \pm 5.3$ & $27.6 \pm 5.0$ & $<0.001$ \\
\hline SBP $(\mathrm{mmHg})$ & $141.7 \pm 27.7$ & $136.6 \pm 26.7$ & $128.7 \pm 22.7$ & $131.7 \pm 19.6$ & $<0.001$ \\
\hline $\mathrm{DBP}(\mathrm{mmHg})$ & $85.0 \pm 14.3$ & $83.5 \pm 14.9$ & $80.1 \pm 13.8$ & $81.8 \pm 12.4$ & $<0.05$ \\
\hline SKI (mm) & $30.0 \pm 9.6$ & $28.0 \pm 9.1$ & $24.9 \pm 8.1$ & $25.0 \pm 8.2$ & $<0.001$ \\
\hline Glucose (mg/dL) & $93.4 \pm 15.3$ & $93.2 \pm 23.3$ & $91.3 \pm 15.8$ & $98.1 \pm 26.8$ & $<0.05$ \\
\hline TC (mg/dL) & $194.4 \pm 39.5$ & $186.1 \pm 37.4$ & $193.0 \pm 39.6$ & $192.4 \pm 38.9$ & 0.242 \\
\hline HDL-c (mg/dL) & $46.4 \pm 11.4$ & $46.4 \pm 10.7$ & $47.3 \pm 11.0$ & $43.8 \pm 10.4$ & $<0.05$ \\
\hline LDL-c (mg/dL) & $127.7 \pm 41.4$ & $120.1 \pm 38.5$ & $126.1 \pm 40.9$ & $128.0 \pm 39.7$ & 0.273 \\
\hline TG (mg/dL) & $101.4 \pm 34.9$ & $98.0 \pm 38.3$ & $98.1 \pm 42.1$ & $103.2 \pm 44.2$ & 0.588 \\
\hline
\end{tabular}

$N$ number of individuals, WC waist circumference, $H C$ hip circumference, $B M I$ body mass index, SBP systolic blood pressure, DBP diastolic blood pressure, SKI Sokolow-Lyon index, TC total cholesterol, TG triglycerides. Data are reported as the mean \pm standard deviation. 
Table 3 Prevalence of cardiovascular risk factors according to gender

\begin{tabular}{llll}
\hline Risk factors & $\begin{array}{l}\text { Men } \\
(\mathbf{N}=\mathbf{2 9 4})\end{array}$ & $\begin{array}{l}\text { Women } \\
\mathbf{( N = 3 2 1 )}\end{array}$ & $\begin{array}{l}\text { All } \\
\mathbf{( N = 6 1 5 )}\end{array}$ \\
\hline Hypertension & $\mathbf{N}(\%)$ & $\mathbf{N}(\%)$ & $\mathbf{N}(\%)$ \\
TC $\geq \mathbf{2 4 0} \mathbf{~ m g / D I}$ & $136(46.3)$ & $142(44.2)$ & $278(45.2)$ \\
LDL-c $\geq \mathbf{1 6 0} \mathbf{~ m g / d L}$ & $31(10.5)$ & $37(11.5)$ & $68(11.1)$ \\
Low HDL-c (mg/dL) & $108(20.8)$ & $60(18.9)$ & $121(19.8)$ \\
TG $\geq \mathbf{1 5 0} \mathbf{~ m g / d L ~}$ & $37(12.6)$ & $28(8.7)$ & $65(10.6)$ \\
Smoking history & $30(10.2)^{*}$ & $14(4.4)$ & $44(7.2)$ \\
Diabetes & $16(5.5)$ & $19(5.9)$ & $35(5.7)$ \\
Overweight & $80(27.3)$ & $100(31.2)$ & $180(29.3)$ \\
Obesity & $27(9.2)^{*}$ & $93(29.0)$ & $120(19.6)$ \\
Sedentary lifestyle & $244(83.0)^{*}$ & $292(91.0)$ & $536(87.2)$ \\
LVH & $94(32.0)^{*}$ & $29(9.0)$ & $123(20.0)$ \\
\hline
\end{tabular}

Hypertension: $\mathrm{SBP} \geq 140 \mathrm{mmHg}$ and/or $\mathrm{DBP} \geq 90 \mathrm{mmHg}$ or normotensive on antihypertensive medication. TC: total cholesterol; LDL-c: low-density lipoprotein cholesterol; HDL-c: low high-density lipoprotein cholesterol (men, $<40 \mathrm{mg} / \mathrm{dL}$; women, $<50 \mathrm{mg} / \mathrm{dL}$ ); TG: triglycerides; diabetes: fasting glucose $\geq 126 \mathrm{mg} / \mathrm{dL}$; overweight: BMI between 25 and $29.9 \mathrm{~kg} / \mathrm{m}^{2}$; obesity: BMI $\geq 30.0$ $\mathrm{kg} / \mathrm{m}^{2}$; LVH: left ventricular hypertrophy (Sokolow-Lyon index $\geq 3.5 \mathrm{mV}$ ). (*) $\mathrm{P}<0.01$ men vs women

In the sample of 615 participants, $88.3 \%(\mathrm{n}=543)$ showed normal blood glucose levels, 6.0\% $(\mathrm{n}=37)$ had decreased glucose tolerance, $3.3 \%(\mathrm{n}=20)$ were diabetics under treatment, and $2.4 \%(\mathrm{n}=15)$ were diabetics who were unaware of their status until the time of this evaluation. Thus, the overall prevalence of diabetes mellitus was $5.7 \%$, and the distribution of diabetes between the genders was similar (men 5.5\%, women 5.9\%). Among the socioeconomic classes (low $3.2 \%$, middle 3.8\%, upper middle $7.2 \%$, upper $8.5 \%$; $\mathrm{P}=0.134$ ), although no significant differences were found, it is noteworthy that the upper socioeconomic class had a relatively higher prevalence of diabetes than the low socioeconomic class.

Overweight was found in $29.3 \%$ of the sample population, with similar distribution in both genders $\left(\mathrm{X}^{2}=1.151\right.$, $\mathrm{P}=0.886$ ). Obesity, however, was three times more prevalent in women (Table 3). A clear increase of prevalence of overweight and obesity was observed from the lowest to upper socioeconomic classes (Table 4), where $68 \%$ showed excessive body weight (body mass index $\geq 25 \mathrm{~kg} / \mathrm{m}^{2}$ ).

The overall prevalence of sedentary lifestyle was $87.2 \%$, and it was higher $\left(\mathrm{X}^{2}=8.712, \mathrm{P}<0.05\right)$ in women $(91.0 \%$; than in men (83.0\%). Individuals of the low socioeconomic class were more inactive than those in the upper socioeconomic class. The overall prevalence of LVH was $20.0 \%$, and it was more prevalent $\left(X^{2}=50.46 ; \mathrm{P}<0.05\right)$ in men (32.0\%) than in women (9.0\%). There was a higher percentage of LVH in the low socioeconomic class (30.5\%) than in the upper socioeconomic class (14.4\%).

Distribution of the number of cardiovascular risk factors is shown in Table 5, with similar values between genders. It is important to note that only $25.7 \%$ of the participants were free from modifiable cardiovascular risk factors and around $50 \%$ of the sample showed two or more risk factors to cardiovascular disease. Figure 1 illustrates the proportion of cardiovascular risk factors according to socioeconomic classes. We observed that the presence of three or more risk factors was higher in the low socioeconomic class $\left(\mathrm{X}^{2}=23.766, \mathrm{P}<0.05\right)$ than in the upper class.

\section{Discussion}

Determination of the prevalence of cardiovascular risk factors in adults has been conducted in several parts

Table 4 Prevalence of cardiovascular risk factors according to socioeconomic class

\begin{tabular}{|c|c|c|c|c|c|}
\hline Socioeconomic class & Low & Middle & Upper middle & Upper & $P$ \\
\hline Risk factor & N (\%) & N (\%) & N (\%) & N (\%) & \\
\hline Hypertension & $86(30.9)$ & $68(24.5)$ & 55 (19.8) & $69(24.8)$ & $<0.05$ \\
\hline $\mathrm{TC} \geq 240 \mathrm{mg} / \mathrm{dL}$ & $20(13.0)$ & $11(07.1)$ & $19(12.5)$ & $18(11.8)$ & 0.483 \\
\hline $\mathrm{LDL}-\mathrm{c} \geq 160 \mathrm{mg} / \mathrm{dL}$ & $34(22.2)$ & $26(17.0)$ & $29(19.1)$ & $32(20.9)$ & 0.899 \\
\hline Low HDL-c (mg/dL) & $72(23.4)$ & $77(25.0)$ & $70(22.7)$ & $89(28.9)$ & 0.128 \\
\hline $\mathrm{TG} \geq 150 \mathrm{mg} / \mathrm{dL}$ & $16(24.6)$ & $16(24.6)$ & $13(20.0)$ & $20(30.8)$ & 0.641 \\
\hline Smoking history & $22(50.0)$ & $10(22.7)$ & $08(18.2)$ & $04(09.1)$ & $<0.001$ \\
\hline Diabetes & $05(14.3)$ & $06(17.1)$ & $11(31.4)$ & $13(37.1)$ & 0.134 \\
\hline Overweight & $33(18.3)$ & $42(23.3)$ & $43(24.0)$ & $62(34.4)$ & $<0.001$ \\
\hline Obesity & $18(15.0)$ & $26(21.7)$ & $34(28.3)$ & $42(35.0)$ & $<0.001$ \\
\hline Sedentary lifestyle & $147(95.5)$ & $139(89.1)$ & $132(86.8)$ & $118(77.1)$ & $<0.001$ \\
\hline LVH & $47(38.2)$ & $32(26.0)$ & $22(17.9)$ & $22(17.9)$ & $<0.001$ \\
\hline
\end{tabular}

Hypertension: SBP $\geq 140 \mathrm{mmHg}$ and/or DBP $\geq 90 \mathrm{mmHg}$ or normotensive on antihypertensive medication; TC: total cholesterol; LDL-c: low-density lipoprotein cholesterol; HDL-c, high-density lipoprotein cholesterol (men, $<40 \mathrm{mg} / \mathrm{dL}$; women, $<50 \mathrm{mg} / \mathrm{dL}$ ); TG: triglycerides; diabetes: fasting glucose $\geq 126 \mathrm{mg} / \mathrm{dL}$; overweight: BMI between 25 and $29.9 \mathrm{~kg} / \mathrm{m}^{2}$; obesity: BMI $\geq 30.0 \mathrm{~kg} / \mathrm{m}^{2} ; \mathrm{LVH}$, left ventricular hypertrophy (Sokolow-Lyon index $\geq 3.5 \mathrm{mV}$ ). 
of the world; however, few studies were performed in African populations and to our knowledge, there have been no studies conducted in Angola. In this study, the prevalence of cardiovascular risk factors was investigated in the adult population of public-sector workers at UAN, which is the oldest public institution of higher education in Angola.

Illiteracy and low education levels are prevalent in low-income countries, and it is known that there is a strong correlation of illness and death with poverty. A low level of education is one of the major determinants of disease and mortality because it is associated with malnutrition and acute and chronic infections [21]. Although the participants of this study worked in an institution of higher education, the prevalence of low education level was $34.6 \%$. This figure is similar to the Angolan norm because, according to the Inquiry into the Welfare of the Population [10], illiteracy in the Angolan population aged 15 years and older was $34.4 \%$. In Africa, the illiteracy rate varies from 10 to $87.2 \%$ [22]. In a study conducted in India, the illiteracy rate was found to be $45.3 \%$ for women and $17.0 \%$ for men, and there was an inverse relationship between education and mortality from all causes [23]. Education increases people's communication skills, reduces inequalities in the knowledge of disease transmission, and provides new opportunities in the production and marketing sectors. The improvement of education is thus crucial for the prevention, early diagnosis, and adequate management of chronic disease risk factors.

Therefore, education serves as a social catalyst.

Socioeconomic inequalities remain one of the main constraints to sustainable development in Africa. The percentage of our sample group in the low socioeconomic class was slightly less than that reported by IBEP [10], where the proportion of the Angolan population living below the national poverty line was found to be $33.6 \%$.

Previous studies have reported that more individuals from low socioeconomic groups die from acute coronary events compared with individuals from high socioeconomic groups [24]. Angola is a low-income country,

Table 5 Cardiovascular risk factors according to gender

\begin{tabular}{llll}
\hline Risk factors & Men & Women & All \\
\hline None & N (\%) & N (\%) & N (\%) \\
One risk factor & $74(25.2)$ & $84(26.2)$ & $158(25.7)$ \\
Multiple risk factors & $78(26.5)$ & $92(28.5)$ & $170(27.7)$ \\
Two & $49(16.6)$ & $45(14.0)$ & $94(15.2)$ \\
Three & $57(19.4)$ & $62(19.3)$ & $119(19.4)$ \\
$\geq$ Four & $36(12.3)$ & $38(12.0)$ & $74(12.0)$ \\
Total & $294(100)$ & $321(100)$ & $615(100)$ \\
\hline
\end{tabular}

No difference between genders was found (chi-square test). where many regions remain at an early stage of epidemiological transition, with sequelae from a long civil war and large pockets of poverty. These factors certainly negatively affect Angola's sustainable development, particularly taking into account the early death of the work force.

The prevalence of hypertension in the current study was $45.2 \%$, which is a higher value than those reported in other African countries, such as South Africa [25], Uganda [26], Nigeria [27], Ethiopia [28], and Ghana [29], where the prevalence of hypertension varied from $13.7 \%$ in rural areas to $30.5 \%$ in urban areas. The SBP of individuals in the low socioeconomic class was higher than that of individuals in the upper class. Similarly, the prevalence of hypertension was higher in the low socioeconomic class than in the upper class. These findings may be associated with psychosocial factors related to poverty, chronic stress at work in activities that involve physical exhaustion [30], and limited access to antihypertensive drugs.

The mean blood glucose level in the upper class was higher than those in the low class. The prevalence of diabetes in our study was similar in both genders. These values are higher than those found in a rural community of Angola (2.8\%) [31]; however, our values are close to those found in the adult population of urban Ghana (6.3\%) [32]. Nevertheless, the prevalence of diabetes in the present study was lower than in Cameroon (10.4\%) [33] and Afro-Surinamese (14.2\%) [34].

The benefits of low cholesterol in the primary and secondary prevention of CVD are clear. The mean cholesterol level found in this study was normal according to the previously defined points. The overall prevalence of hypercholesterolemia was lower than the values previously reported for Nigeria (28.3\%) [27] and African-Americans (28.9\%) [35]. Although no significant difference was found, the prevalence of hypercholesterolemia in the low socioeconomic class was slightly higher than that in the upper socioeconomic class. The prevalence of low HDL was high, and more women were affected than men. This discrepancy is likely because the majority of women included in the study were premenopausal phase since the mean age of the women was $44.0 \pm 10.1$ years. Regarding socioeconomic status, although no significant difference was found, there was a trend to higher HDL levels in the upper class. The proportion of high LDL (19.8\%) was similar between genders and between different socioeconomic classes.

The prevalence of hypertriglyceridemia was similar to the prevalence found in the Nigerian population (15.0\%) [27] but lower than the prevalence found in the third National Survey on Health and Nutrition (NHANES III) in African-American men and women (21.0 and 14.0\%, respectively) [35]. 


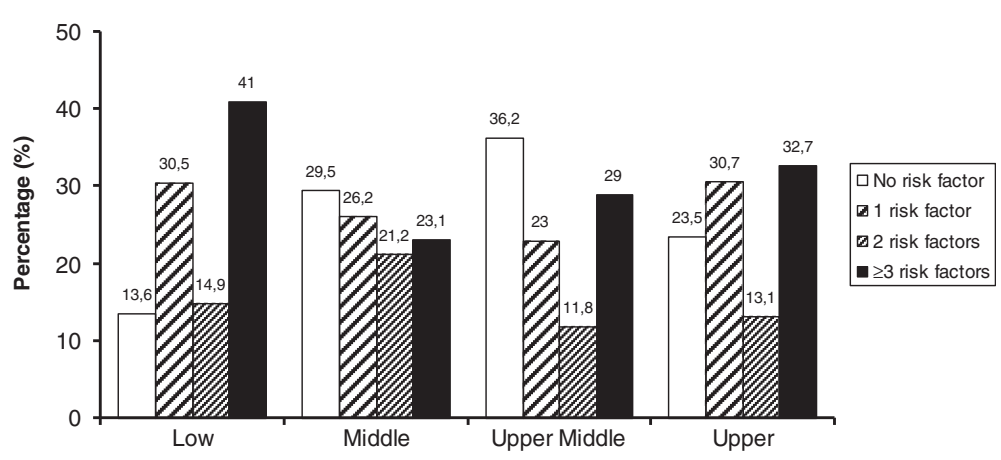

Figure 1 Proportion of cardiovascular risk factors according to socioeconomic classes.

The BMI was higher in women than in men, and a direct relationship with socioeconomic status was found, namely, BMI progressively increased as socioeconomic status increased. This finding was marked in men and was also observed with regard to waist circumference (WC), where $62.3 \%$ of women and $15.3 \%$ of men exhibited values higher than recommended [16]. Angola is a low- income country, but overweight and obesity appear to coexist with undernutrition and malnutrition. In 2006, the overall prevalence of malnutrition was $44.0 \%$ [36], and $20.0 \%$ of children die from this cause [37]. Excessive weight increases the probability of obesity and weight-related disorders. In this study, the prevalence of obesity was higher in women than in men.

Overweight and obesity are prevalent in many countries, and according to Nishida and Mucavele [38], the prevalence of obesity is higher in women than in men in countries such as Egypt (33.0 vs. 12.6\%), South Africa (30.1 vs. 9.4\%), and the Seychelles Islands (28.2 vs. $8.5 \%$ ). Nutrition plays a significant role in many risk factors associated with CVD. Considering that approximately $49.0 \%$ of the sample population had body weights above the recommended values, it is necessary to take preventative measures to mitigate future complications. Physical inactivity is a malady of the modern world because the comfort provided by various types of technology and the consumption of highly caloric industrialized food contribute to weight gain and, consequently, a decreased quality of life. The prevalence of physical inactivity found in this study was very high, and women were more inactive than men. Similar data were reported for the population of Porto, Portugal (84.0\%) [39].

The prevalence of smoking was low, although it was higher in men than in women. These data are similar to those reported by Tran et al. in Ethiopia [28] and by Addo et al. in Ghana [40]. In general, smoking prevalence among African women is low, likely because smoking is not a culturally well-accepted habit for this gender. Nevertheless, it is necessary to continue policies aimed at reducing the use of tobacco even further.
The progressive remodeling of the left ventricle (LV) is directly related to the further deterioration of cardiac performance and a less favorable outcome in presence of CVD [41]. LVH is an adaptive response of the myocardium to increased cardiac work, resulting in increased cardiac mass, which can lead to ventricular arrhythmias, myocardial ischemia, systolic and diastolic ventricular dysfunction, and sudden death [42]. The prevalence of $\mathrm{LVH}$ was higher in men than in women, and the low socioeconomic class was more affected than the upper class. The high prevalence of hypertension found in the low socioeconomic class is due to discrepancies in the prevalence of LVH among socioeconomic classes.

This study demonstrated the existence of a high prevalence of modifiable risk factors for cardiovascular disease among the study participants, such as hypertension, low HDL level, overweight, obesity, sedentary lifestyle, and $\mathrm{LVH}$, rendering them more likely to be affected by a cardiovascular event, especially when associated with low socioeconomic status, as the majority of individuals with this status had three or more risk factors. Because this sample is a convenience sample, generalization of the findings in the present study to a wider Angolan population may be limited; however, our findings serve as indicators of the health of workers in Angola because all socioeconomic groups in this country were represented.

\section{Conclusions}

Our study suggests the existence of a high prevalence of multiple risk factors for cardiovascular disease in apparently healthy public-sector workers in Angola, and that the socioeconomic groups with lower incomes were more affected by hypertension, smoking, and LVH. The coexistence of multiple risk factors in this population indicates the necessity to intensify efforts for the prevention, early identification, and control of risk factors, especially in the lower-income segments of the population, which represents the priority group for intervention and the promotion of cardiovascular health. 


\section{Competing interests}

The authors declare that they have no competing interests in this work.

\section{Authors' contributions}

DPC, PM, and JGM designed the study. DPC and AVLF explained the study to the workers at the Schools and Institutes. ABTS, MAAG, CCFS, AVLF, and $\mathrm{PM}$ participated in the data collection and managed the equipment in the work space. DPC wrote the article and was responsible for data management, interpretation of the results, and conducting the literature review. MPB and SLR assisted with the data analysis and the writing of the paper. JGM coordinated the study and participated in all stages of the writing. All authors read and approved the final manuscript.

\section{Acknowledgments}

We appreciate the cooperation of the public-sector workers at UAN and the great work of the laboratory technicians. This study was supported by the Science and Development Foundation of Agostinho Neto University, Angola, Africa, and by CAPES (the Brazilian Federal Agency for the Support and Evaluation of Higher Education).

\section{Author details}

'Department of Physiological Sciences, Federal University of Espírito Santo, Espírito Santo, Brazil. ${ }^{2}$ Department of Physiological Sciences, Medical School of the Agostinho Neto University, Luanda, Angola.

\section{Received: 15 June 2012 Accepted: 10 June 2013}

Published: 7 August 2013

\section{References}

1. Yusuf S, Srinath R, Ounpuu S, Anand S: Global burden of cardiovascular diseases Part II. Variations in cardiovascular disease by specific ethnic groups and geographic regions and prevention strategies. Circulation 2001, 104:2855-2864.

2. Mackay J, Mensah G: Atlas of heart disease and stroke. Geneva: World Health Organization; 2004

3. Murray CJL, Lopez AD: The Global Burden of Disease. A comprehensive assessment of mortality and disability from diseases, injuries and risk factors in 1990 and projected to 2020, Volume GBD Series I. Cambridge, Massachusetts: Harvard School of Public Health on behalf of the World Health Organization and the World Bank; 1996.

4. Lopez AD, Mathers CD, Ezzati M, Jamison DT, Murray CJL: Global burden of disease and risk factors. Oxford England: Oxford University Press and Washington, DC, the World Bank; 2006.

5. Hattersley I: Trends in life expectancy by social class: An update. Health Statistic Quarter 1999, 2:16-24.

6. Winkleby MA, Cubbin C: Influence of individual and neighborhood socioeconomic status on mortality among black, Mexican-American, and white women and men in the United States. J Epidemiol Comm Health 2003, 57:444-452.

7. Lewis CE, Smith DE, Wallace DD, Williams OD, Bild DE, Jacobs DR: Seven- year trends in body weight and associations with lifestyle and behavioral characteristics in black and white young adults: The CARDIA study. Am J Public Health 1997, 87:635-642.

8. Genest J, McPherson R, Frohlich J, Anderson T, Campbell N, Carpentier A Couture P, Dufour R, Fodor G, Francis GA, Grover S, Gupta M, Hegele RA, Lau DC, Leiter L, Lewis GF, Lonn E, Mancini GBND, Pearson GJ, Sniderman A, Stone JA, Ur E: Canadian guidelines for the diagnosis and treatment of dyslipidemia and prevention of cardiovascular disease in the adult - 2009 recommendations. Can J Cardiol 2009, 25:567-579.

9. World Bank: Esperança de vida em Angola. 2009. Available at: http://www. tradingeconomics.com/angola/mortality-rate-infant-per-1-000-live-births-wb-data. html. (Accessed on 09/02/2012).

10. IBEP - Inquérito Integrado Sobre o Bem-Estar da População: Taxa de mortalidade em crianças abaixo de 5 anos de idade em 2009, Volume Volume II. 2011. Available at: http://www.childinfo.org/files/Angola_IBEP_200809 Relatorio de Tabelas Vol2 Por.pdf. (Accessed on 09/02/2012).

11. World Health Organization: Chronic diseases and health promotion: Stepwise approach to surveillance (STEPS). Geneva; 2004. Available at: http://www.who.int/chp/steps/instrument/en/index.html.

12. Ministério do Planejamento da República de Angola: Estratégia de combate à pobreza. Reinserção social, reabilitação e reconstrução e esbabilização econômica, Edição revista. 2005. Available at: http://mirror.undp.org/angola/ linkrtf/ecp-angola2005.pdf.

13. World Health Organization: Socioeconomic classification, physical activity, Health interview surveys: Towards international harmonization of methods and instruments, Volume Volume 58. European series: WHO regional publications; 1996.

14. Hu G, Tuomilehto J, Silventoinnen K, Barengo N, Jousilahti P: Joint effects of physical activity, body mass index, waist circumference, and waist-tohip ratio with the risk of cardiovascular disease among middle-aged Finnish men and women. Eur Heart J 2004, 25:2212-2219.

15. JNC VII: The Seventh Report of the Joint National Committee on the Prevention, Detection, Evaluation and Treatment of High Blood Pressure. JAMA 2003, 289:2560-2572.

16. World Health Organization: Obesity: Preventing and managing the global epidemic, Volume 894. Geneva: Report of a WHO consultation. WHO technical report; 2000.

17. Friedwald WT, Levy RI, Fredrickson DS: Estimation of the concentration of low-density cholesterol in plasma without the use of the preparative ultracentrifuge. Clin Chem 1972, 18:449-502

18. Executive Summary of the Third Report of the National Cholesterol Education Program (NCEP) Expert Panel on Detection, Evaluation, and Treatment of High Blood Cholesterol in Adults (Adult Treatment Panel III). JAMA 2001, 285:2486-2497.

19. Gakidou E, Mallinger L, Abbott-Klafter J, Guerrero R, Villalpando S, Ridaura RL, Aekplakorn W, Naghavi M, Lim S, Lozano R, Murray CJL: Management of diabetes and associated cardiovascular risk factors in seven countries: a comparison of data from national health examination surveys. Bull World Health Organ 2011, 89:172-183.

20. Sokolow M, Lyon TP: The ventricular complex in left ventricular hypertrophy as obtained by unipolar precordial and limb leads. Am Heart J 1949, 37:161-186.

21. Marmot MG, Smith GD, Stansfeld S, Patel C, North F, Head J, White I, Brunner E, Feeney A: Health inequalities among British civil servants: The Whitehall II study. Lancet 1991, 337:1387-1393.

22. WRI - World Resources Institute: Earth trends The environmental information portal. Washington, DC; 2005. Available: http://pdf.wri.org/ worldresources 2005 brochure.pdf. (Accessed 22/03/2012).

23. Pednekar MS, Gupta R, Gupta PC: Illiteracy, low educational status, and cardiovascular mortality in India. BMC Publ Health 2011, 11:567.

24. Xavier D, Pais P, Devereaux PJ, Xie C, Prabhakaran D, Reddy KS, Gupta R, Joshi P, Kerkar P, Thanickachalam S, Haridas KK, Jaison TM, Naik S, Maity AK, Yusuf S, on behalf of the CREATE Registry Investigators: Treatment and outcomes of acute coronary syndromes in India (CREATE): a prospective analysis of registry data. Lancet 2008, 371:1435-1442.

25. Mollentze WF, Moore AJ, Steyn AF, Joubert G, Steyn K, Oosthuizen GM, Weich DJV: Coronary heart disease risk factors in rural and urban Orange Free State black populations. S Afr Med J 1995, 85:90-96.

26. Wamala JF, Karyabakabo Z, Ndungutse D, Guwatudde D: Prevalence factors associated with hypertension in Rukungiri district, Uganda - A community-based study. Afr Health Sci 2009, 9:153-160.

27. Sani MU, Wahab KW, Yusuf BO, Gbadamosi M, Johnson OV, Gbadamosi A: Modifiable cardiovascular risk factors among an apparently healthy adult Nigerian population - a cross-sectional study. BMC Res Notes 2010, 3:11.

28. Tran A, Gelaye B, Girma B, Lemma S, Berhane Y, Bekele T, Khali A, Williams MA: Prevalence of metabolic syndrome among working adults in Ethiopia. Inter J Hypertens 2011, 2011:193719.

29. Twagirumukiza M, Bacquer D, Kips JG, Backer G, Stichele RV, Bortel LMV: Current and projected prevalence of arterial hypertension in sub- Saharan Africa by sex, age, and habitat: an estimate from population studies. J Hypertens 2011, 29:1243-1252.

30. Marmot MG, Bosma H, Hermingway H, Bruner E, Stansfeld S: Contribution of job control and other risk factors to social variations in coronary heart disease incidence. Lancet 1997, 350:235-239.

31. Evaristo-Neto AD, Foss-Freitas MC, Foss MC: Prevalence of diabetes mellitus and impaired glucose tolerance in a rural community of Angola. BMC Diabetology \& Metabolic Syndrome 2010, 2:63.

32. Abubakari AR, Bhopal RS: Systematic review on the prevalence of diabetes, overweight/obesity, and physical inactivity in Ghanaians and Nigerians. Public Health 2008, 122:173-182. 24.

33. Levitt NS: Diabetes in Africa epidemiology, management, and healthcare challenges. Heart 2008, 94:1376-1382 
34. Bindraban NR, van Valkengoed IGM, Mairuhu G, Holleman F, Hoeskstra JB, Michels BP, Koopmans RP, Stronks K: Prevalence of diabetes mellitus and the performance of a risk score among Hindustani Surinamese, African Surinamese, and ethnic Dutch: a cross-sectional population-based study. BMC Publ Health 2008, 8:271.

35. Centers for Disease Control and Prevention: Trends in cholesterol screening and awareness of high blood cholesterol - United States, 1991-2003. Morbidity Mortality Weekly Report MMWR 2005, 54:865-870.

36. Pinto JN: Direito à alimentação e segurança alimentar e nutricional nos países da CPLP, FAOSTAT. 2011. Available at: http://farmersplatform.weebly.com/uploads/5/ 6/8/7/5687387/esan-cplp_diagnostico_de_base.pdf. (Accessed on 09/02/2012).

37. UNICEF - United Nations Children's Fund: Mortality due to malnutrition in Angolan Children. 2012. Available at: http://www.afrol.com/articles/16767. (Accessed on 28/03/2012).

38. Nishida C, Mucavele P: Overweight and Obesity a new Nutrition Emergency? Monitoring the rapidly emerging public health problem of overweight and obesity: The WHO global database on Body Mass Index. SCN News 2005, 29. Available at: http://www.unsystem.org/scn/Publications/ SCNNews/scnnews29.pdf.

39. Gal DL, Santos AC, Barros H: Leisure-time versus full-day energy expenditure: A cross-sectional study of sedentarism in a Portuguese urban population. BMC Publ Health 2005, 5:16.

40. Addo J, Smeeth L, Leon DA: Smoking patterns in Ghanaian civil servants: Changes over three decades. Inter J Environ Res Public Health 2009, 6:200-208.

41. Mann DL: Left ventricular size and shape: determinants of mechanical signal transduction pathways. Heart Failure Rev 2005, 10:95-100.

42. Muiesan ML, Salvetti M, Monteduro C, Bonzi B, Paini A, Viola S, Poisa P, Rizzoni D, Castellano M, Agabiti-Rosei E: Left ventricular concentric geometry during treatment adversely affects cardiovascular prognosis in hypertensive patients. Hypertension 2004, 43:731-738.

doi:10.1186/1471-2458-13-732

Cite this article as: Capingana et al:: Prevalence of cardiovascular risk factors and socioeconomic level among public-sector workers in Angola. BMC Public Health 2013 13:732.

\section{Submit your next manuscript to BioMed Central and take full advantage of:}

- Convenient online submission

- Thorough peer review

- No space constraints or color figure charges

- Immediate publication on acceptance

- Inclusion in PubMed, CAS, Scopus and Google Scholar

- Research which is freely available for redistribution 